\title{
The Connected Qualities of Design Thinking and Maker Education practices in Early Education: A narrative review
}

\author{
Annemiek Veldhuis \\ a.h.m.veldhuis@tue.nl \\ Department of Industrial Design, \\ Eindhoven University of Technology \\ Eindhoven, The Netherlands \\ Ioanna Garefi \\ ioanna.gaferi@stimmuli.eu \\ STIMMULI for Social Change \\ Thessaloniki, Greece \\ Silvia Remotti \\ silvia@pacollaborative.com \\ PACO design collaborative \\ Milano, Italy
}

\author{
Bernice d'Anjou \\ bed6704@nyu.edu \\ Educational Communication and \\ Technology, New York University \\ Steinhardt \\ New York City, New York, USA \\ Panagiota Digkoglou \\ giota.digkoglou@stimmuli.eu \\ STIMMULI for Social Change \\ Thessaloniki, Greece \\ Emer Beamer Cronin \\ emer@designathon.nl \\ Designathon Works \\ Amsterdam, The Netherlands
}

\author{
Tilde Bekker \\ m.m.bekker@tue.nl \\ Department of Industrial Design, \\ Eindhoven University of Technology \\ Eindhoven, The Netherlands
}

Georgia Safouri

georgiasafouri@yahoo.com

Aristotelio College

Thessaloniki, Greece

Madalina Bouros

bourosmadalina@gmail.com

AllGrow

Cimpineanca, Romania

\begin{abstract}
Design Thinking (DT) and Maker Education (ME) are fairly new approaches that aim to equip students with skills for the 21st century. As DT and ME both involve a design process, these might be combined. To guide design processes that aim to combine DT and ME in early education, we review 28 formal and non-formal educational practices aimed at children 8 to 14 years old that have incorporated DT or ME over the past 10 years. We analyse their qualities in terms of their Objectives, Learning Activities, the Teacher's Role, and Assessment Activities. From our findings, we develop an overview that showcases the connections between these qualities within the selected practices. We found that not all components were aligned well. Therefore, we outline the DT and ME Curriculum Blueprint, a tool aimed to support reflection on the alignment between these components in the development of DT and ME practices in early education.
\end{abstract}

\section{CCS CONCEPTS}

- Social and professional topics $\rightarrow$ Model curricula; Informal education; Computational science and engineering education; Computing literacy; • General and reference $\rightarrow$ Surveys and overviews.

\section{KEYWORDS}

Design Thinking, Maker Education, Curriculum development, Narrative review

CC)
This work is licensed under a Creative Commons Attribution International
4.0 License.
FabLearn Europe / MakeEd 2021, June 2-3, 2021, St. Gallen, Switzerland
(C) 2021 Copyright held by the owner/author(s).
ACM ISBN 978-1-4503-8989-1/21/06.
https://doi.org/10.1145/3466725.3466729

ACM Reference Format:

Annemiek Veldhuis, Bernice d'Anjou, Tilde Bekker, Ioanna Garefi, Panagiota Digkoglou, Georgia Safouri, Silvia Remotti, Emer Beamer Cronin, and Madalina Bouros. 2021. The Connected Qualities of Design Thinking and Maker Education practices in Early Education: A narrative review. In FabLearn Europe / MakeEd 2021 - An International Conference on Computing, Design and Making in Education (FabLearn Europe / MakeEd 2021), June 2-3, 2021, St. Gallen, Switzerland. ACM, New York, NY, USA, 10 pages. https://doi.org/10.1145/3466725.3466729

\section{INTRODUCTION}

The limitations of the traditional education system have encouraged efforts to rethink how education should be used to equip students with the skills needed to address the challenges of the 21st century. Maker Education (ME) and Design Thinking (DT) in education aim to nurture 21st-century skills [64] in students through creative making processes $[31,61]$. Through these approaches, students are enabled to discover knowledge instead of receiving it passively [38]. DT in education can be defined as project-based learning in which students gather and process knowledge while working on the design of yet unknown 'products' that relate to the student's personal worlds [44, $58,60]$. And ME as project-based learning through activities focussed on designing, building, modifying, and/or repurposing material objects oriented toward making, through traditional craft techniques or digital technologies, a sort of 'product' that can be used, interacted with, or demonstrated $[30,44,50]$. The two approaches have overlap as they both involve ideating, creating, and reflecting on experience and can, therefore, be combined [40, 51, 61]. By combining DT and ME in early education, young children can be better prepared for the difficulties of today and those that may emerge in the future [40, 61].

Many practices have been designed to implement either of these approaches in the school-setting or to introduce them to children through informal methods such as after-school care activities. Previous work has noted the importance of integrating these practices 
in the school curriculum $[34,54]$ and, as the teacher has major control over formal teaching activities, the involvement of teachers $[25,28,39,62]$. To be able to be embedded in a formal school setting, constructivist teaching practices should align their learning objectives with their learning activities and assessment procedures [28] while reflecting on the role of the teacher in the process $[25,39,62]$. When these aspects are well-aligned, they are likely to contribute to higher quality practices [28]. Moreover, for informal practices it would also be beneficial to reflect on the relationship between these aspects to improve their quality. To support design practitioners and educators with design decision-making when creating new educational materials for early education that combine DT and ME, we aim to uncover and describe the qualities that inhabit these aspects and the connections between them in contemporary formal and informal practices.

So far, DT has been reviewed in terms of its learning outcomes [63] and its qualities in higher education, either within educational programs or courses [37,47]. This bypasses the needs of young children in curriculum development [57]. With regard to ME practices, several aspects have been reviewed: the materials that were used in these practices $[41,55]$, the subject areas that they were applied to $[41,55]$, teachers' roles [41], and learning and assessment objectives [26]. However, no review has yet been conducted that analyses the alignment between learning objectives, learning activities, and assessment activities in DT and ME practices.

We want to combine information on how these aspects are implemented in contemporary DT and ME practices and contribute an overview that can inform future design practitioners and/or teachers in making informed design decisions towards internal consistency of the DT and ME practices that they design. Consequently, we pose the following initial research questions: What are the qualities of contemporary formal and informal practices that incorporate $D T$ and/or ME in terms of learning objectives, learning activities, the teacher's role, and assessment activities and to which extent are they related and aligned? To answer our research questions, we review the qualities of $\mathbf{2 8}$ practices that have been applied in the past 10 years. We do not aim to offer a comprehensive review of the state-of-the-art, but of a substantive sample that may reveal crucial or common aspects.

In addition to contributing substantive findings regarding the different qualities of DT and ME and their connections, this review also outlines the DT and ME Curriculum Blueprint, a tool that aims to aid reflection upon the interlinked aspects of a DT and ME curriculum to support future curriculum development.

\section{METHOD}

In this review, we aim to synthesise the qualities of a representative sample of DT and ME practices via a narrative review. A narrative review is commonly used to describe and summarise the current state of emerging issues [56]. We review papers as well as detailed practice-based descriptions (e.g. from websites).

\subsection{Search Strategy}

The narrative review presented below is based on material derived from a selection process that is comprised of three steps: a general search, translation and summarising, and a summary review. 1) A general search was applied to the Google search engine, Google Scholar, and the ACM Digital Library. We attempted to identify DT or ME practices which target children between 8 and 14 years old and were conducted between January 2009 and December $2019^{1}$ (inclusive). The combinations of keywords that were used for this search can be viewed in Table 1 . Websites and articles were read for relevance to the research question. Practices were selected if the described activities within the practices were broadly consistent with the definitions of DT and ME stated in the introduction. For the inclusion of practices of different countries, researchers from four European countries, namely the Netherlands, Greece, Italy, and Romania ${ }^{2}$, participated in selecting the materials, ensuring that practices that were only described in a native language were included. In line with the scope of this review, six researchers selected 5 practices each, resulting in 30 practices that were selected. 2) The information about these selected practices was translated into English if necessary and summarised. 3) The summaries were reviewed. Practices were selected for review if they met the following topic-related criteria: the practice includes DT or ME in either a formal or informal learning environment; the practice targets children aged between 8-14 years old; the practice includes a teacher or facilitator; the practice was conducted in a public environment such as a school, library or FabLab. Practices that did not meet the following quality-related criteria were excluded: the information about the practice does not describe its learning activities; the practice wasn't conducted in the last 10 years. 28 out of 30 practices remained and were included in this review.

\subsection{Review Strategy}

First, we divided these 28 practices in terms of their approach, either mostly DT or primarily ME. When a practice had aspects of both, we coded this practice as the more prominent approach.

To find the qualities of each approach, we analysed the practices in terms of their Learning Objectives, Learning Activities, Teacher Role, and Assessment procedures. We extracted the practices' mission statements, description of learning activities, materials, and assessment procedures from the available information and entered these into a spreadsheet to facilitate data sorting and review. The qualitative data was then analysed by two coders through inductive thematic analysis [32]. The first author was the main coder throughout the analysis. For the various parameters, different second coders were included in the analysis based on their expertise. Results were discussed and agreed upon between the two coders. The few differences that arose were resolved through discussion. Furthermore, to examine the consistency of the practices, we evaluated whether their Assessment procedures were in line with their Learning Objective and Learning Activities.

\section{FINDINGS}

Sample characteristics. As through our inclusion criteria, the practices included either a DT or ME approach. Out of 28 practices, 16 primarily leveraged DT, and 12 were coded as utilising a mostly

\footnotetext{
${ }^{1}$ The submission of this review was delayed by a year due to the COVID-19 pandemic.

${ }^{2}$ This review is part of a European project conducted in these countries.
} 
Table 1: Search strategy keywords

\begin{tabular}{ll}
\hline Categories & Boolean search string \\
\hline DT & "Design Thinking" OR "design-based learning" OR "design education" \\
ME & "making" OR "Maker Education" OR "fabrication" OR "makerspace" \\
Children & "teen" OR "youth" OR "primary education" OR child* OR "secondary education" OR "student" \\
\hline
\end{tabular}

Table 2: Distribution of 28 reviewed practices over their approach and connection to the school curriculum.

\begin{tabular}{|l|l|l|}
\hline Approach & Formality & Source \\
\hline \multirow{2}{*}{ DT (N=16) } & Formal (N=11) & {$[2-5],[10],[14],[19],[20],[33],[36],[59]$} \\
\cline { 2 - 3 } & Informal (N=5) & {$[1],[7],[12],[13],[17]$} \\
\hline \multirow{2}{*}{ ME (N=12) } & Formal (N=7) & {$[8],[9],[11],[15],[16],[49],[52]$} \\
\cline { 2 - 3 } & Informal (N=5) & {$[6],[18],[21-23]$} \\
\hline
\end{tabular}

ME approach (see Table 2). 18 were connected to the school curriculum as projects, whereas 10 were not connected to the school curriculum but aimed to get children familiar with DT or ME through workshops $(N=6)$, a summer school $(N=1)$, an after-school club $(N=1)$, or design challenges $(N=2)$. Five practices were carried out in Romania. Four each in Greece, Italy, the Netherlands, and the US. The remaining practices were carried out in Germany $(N=1)$, Belgium $(N=1)$, Spain $(N=1)$, Singapore $(N=1)$, the Philippines $(N=1)$, Finland $(N=1)$, and over four countries in Europe simultaneously $(N=1)$.

\subsection{Learning Objectives}

Learning objectives concern the anticipated knowledge, skills, and attitudes that students acquire through a practice [24]. Through thematic analysis of the selected practices' mission statement, we arrived at a wide array of aims and objectives stated by both DT and ME practices (see Table 3 for an overview). Moreover, we showcase and discuss the sub-objectives, italicised in the text, out of which these codes are comprised.

$D T$ practices $(N=16)$. Notably, we found that all 16 of the selected DT practices aimed to promote creativity in students. Additionally, the results suggest that supporting interpersonal skills is also a distinct objective of the analysed DT practices. 11 practices explicitly mention that they aim to support collaboration skills. While collaboration is often highlighted as objective, enhancing communication is only mentioned by five practices [5, 7, 13, 14, 59]. And lastly, five practices $[5,10,17,20,59]$ aim to boost empathy in children.

Another set of objectives that are closely related to interpersonal skills that were often mentioned by the DT practices are professional skills. Design for Change [59] aims to boost students' leadership skills. Six practices want to enable students to work on innovations. The Impact Clubs Initiative [1], an afterschool project, aims to support students' ability to innovate by enabling students to create an implementable service design concept. Furthermore, entrepreneurial skills are a dedicated objective for four practices. For example, Progetto SET - Scuola e Territorio [14] aims to instil entrepreneurship skills in students by enabling them to design start-up companies.
Many of the DT practices also aim to develop self-regulation skills in children. The Kids Can! innovation camp [17] and Design Thinking Toolkit [10] focus on developing students' meta-cognitive skills. Designed by Kids [5] aims for students to boost their decisionmaking skills. Lastly, Happiness Makers [12], also aims to boost the participants' self-esteem.

Moreover, critical thinking skills are often cited as an objective. Kids Can! innovation camp [17] tries to support critical thinking through Authentic Learning and the Design Thinking Toolkit [10] wants to aid critical thinking by making students familiar with the context they are designing for. Two other practices want to aid perspective taking [7, 59]. Moreover, three practices $[1,3,20]$ aim to boost students' social awareness by involving perspectives from individuals who are external to the school. Lastly, some practices also apply DT to a pre-defined topic to cultivate the students' problem-solving skills. One practice [33] applies DT to geography and another [17] to sustainability.

ME practices $(N=12)$. Most objectives stated by the selected ME practices revolve around the learning of technical skills. 11 out of the $12 \mathrm{ME}$ practices described their aim to be technology learning. For instance, Vodafone Generation Next [21] aims to support students' skills development regarding new technologies and science through a platform with short educational videos about various technology-related topics (e.g. Arduino basics, Internet of Things, or app development). Dancing Robots [52], a practice in which fifth- and sixth-grade students design a robot together with an engineering student, is the only practice that does not state technology learning as an aim. Nevertheless, they leverage ME activities to support the young students' collaboration skills and instil a positive attitude towards engineers in the children. Teaching making skills was only explicitly mentioned in seven practices. For instance, Maker@Scuola [8] tries to provide students with refined and readyto-use making skills, such as 3D modelling and 3D printing. Moreover, four practices aim to support students in developing computational thinking skills. For example, Designweek@school [16] provides workshops where students can experiment with the Scratch programming language.

While previous objectives were different from DT practices, some $\mathrm{ME}$ practices also mention objectives that are in line with those of 
Table 3: An overview of the coded learning objectives that were pursued in the 16 DT and 12 ME practices.

\begin{tabular}{|l|l|l|}
\hline Objective & DT $\mathbf{( N = 1 6 )}$ & ME $\mathbf{( N = 1 2 )}$ \\
\hline Creativity & {$[1-5,7,10,12-14,17,19,20,36,59]$} & {$[11,15,16,18,22]$} \\
\hline Interpersonal Skills & {$[1-3,5,7,10,13,14,17,20,59]$} & {$[11,15,18,49]$} \\
\hline Technical Skills & & {$[6,8,9,15,16,18,21-23,49,52]$} \\
\hline Professional Skills & {$[1,3,5,12,14,19,20,59]$} & {$[8,11,15,16]$} \\
\hline Self-Regulation & {$[5,10,12,17]$} & {$[22]$} \\
\hline Critical Thinking & {$[1,3,7,10,17,20,59]$} & \\
\hline Problem-Solving & {$[17,33]$} & {$[22]$} \\
\hline
\end{tabular}

DT practices. Five ME practices [11, 15, 16, 18, 22] aim to support creativity in students. Interpersonal skills are represented in the objectives of ME as well. Three practices $[15,18,52]$ want to aid collaboration skills. The Makey Project [49] wants to boost communication skills. Eduact [22] aims for self-regulation by boosting the participants' self-esteem and stated the goal to support the students' problem-solving skills. And lastly, professional skills are represented by practices that want to support innovation $[8,11,16]$.

\subsection{Learning Activities}

The learning activities encompass the whole range of actions that students perform during the learning process. We broadly identified four phases in which these actions take place: 1) research, 2) ideation, 3) creation, and 4) evaluation.

$D T$ practices $(N=16)$. Many practices involve research activities that aim to help students gain insights into the design context. Seven practices provide the possibility for students to do research online (see Table 4), two practices $[19,36]$ give a lecture with background information, and two practices take students to the context by either designing on location [18] or taking them on a field trip [10]. Some practices also allow students to work together with externals to gain insight into their design context and allowing them to empathise with others. Examples of this are students working together with an engineer [2], individuals in the local community [1,59], potential users [20], or local companies [3, 14]. Other practices ask students to design for problems that are close to their world of experience, which requires no research.

All DT practices included some form of ideation activity (see Table 4). Brainstorming activities got accompanied by mind mapping $[14,59]$ or sketching [2, 7] in some cases. Many practices also provide ideation worksheets that aim to support the process. For example, Designathon [7] asks participants to design a solution for several users with different characteristics through a worksheet. Some practices also involve activities that are aimed to stimulate creativity before the start of an ideation activity. For example, Future Designers [36] uses the 'marshmallow challenge' to encourage creative thinking.

When students have an idea, they are asked to create a physical or digital representation that can communicate their idea. Mock-up creation was used in eleven out of sixteen DT practices (see Table 4). These are activities in which children create a proof-of-concept prototype of their ideas through basic materials, such as paper, cardboard, and tape. Designathon [7] also includes basic electronic components in the tools that participants can use to create their mock-up. This mock-up allows students to reflect on the working of their concept and communicate the story of their concepts to others. Other practices also involve other making activities that help the students to communicate their concept. For example, in Eureka [19] and ActivistaICAN [13] students have to create a poster to present their concepts to their peers. The Taking DT to Schools project [33] asks the students to make a video that explains their idea. The students who participate in My Machine [2] sketch the robot to communicate their concept to an engineer.

When students have created their concept in a way that it can be communicated to others. The concept can be evaluated. In three practices $[7,12,36]$ the students have to give a presentation. Teachers can give feedback and assess the students on their mockup or presentation. Some practices are set up as competitions [19, $36]$, in these, the concepts are evaluated by a panel of experts. In the practices that incorporate working with external experts (see Table 4), students can receive feedback from them. Lastly, some practices also incorporate evaluation frameworks $[4,10]$ to allow students to structurally evaluate their concepts.

Throughout these four phases, some practices also require students to take part in overarching activities. Three practices $[1,14$, 59] involve activities in which students have to plan their projects. In Agency by Design [4] students track their process by making it visible and are asked to reflect upon their progress. Other practices also stimulate the setting of learning goals within predefined competencies [5]. Moreover, the students participate in other reflection and assessment activities that assess their development in some practices. These activities will be covered more extensively in section 3.4.

ME practices $(N=12)$. Many activities included in the selected ME practices have overlap with DT practices. In the research phase, five practices $[6,8,11,15,21]$ allow students to do research on the internet and three practices $[6,18,52]$ include a fieldtrip. However, different from DT practices, many ME practices involve instructional activities, such as expert lectures $[6,15]$, online courses $[15,21]$, or introductory workshops $[8,9,15,16,21,49]$ on how to use the new technologies that they will work with within the practice.

Just like in DT practices, we found that ideation activities are common in the selected ME practices. Five out of twelve practices included brainstorm [8, 15, 16, 18, 21] or sketching [52] activities. However, these ideation activities were often more open-ended than those in DT practices as the goal of ideation in these practices was less about solving a complex issue involving other individuals and 
Table 4: An overview of the coded learning activities in the 16 DT and 12 ME practices per process-phase.

\begin{tabular}{|c|c|c|}
\hline Phase & DT $(\mathrm{N}=16)$ & $\operatorname{ME}(\mathrm{N}=12)$ \\
\hline Research & $\begin{array}{l}\text { Research Online }[1,3,4,14,19,20,59], \\
\text { Work with externals }[1-3,14,20,59] \\
\text { Lecture with background information }[19,36] \text {, } \\
\text { Designing on location }[18] \\
\text { Field trip [10] }\end{array}$ & $\begin{array}{l}\text { Introductory workshop }[8,9,15,16,21,49] \text {, } \\
\text { Research online }[6,8,11,15,21], \\
\text { Fieldtrip }[6,18,52] \\
\text { Expert lectures }[6,15] \\
\text { Online courses }[15,21]\end{array}$ \\
\hline Ideation & $\begin{array}{l}\text { Brainstorming }[1-5,7,10,12-14,17,19,20,33,36,59] \text {, } \\
\text { Mindmapping }[14,59] \text {, } \\
\text { Sketching [2, } 7] \text {, } \\
\text { Creativity boosting activities [36] }\end{array}$ & $\begin{array}{l}\text { Brainstorming }[8,15,16,18,21] \text {, } \\
\text { Sketching }[52]\end{array}$ \\
\hline Creation & $\begin{array}{l}\text { Mock-up [3, 5, 7, 10, 12, 14, 17, 19, 33, 36, 59], } \\
\text { Poster making [13,19], } \\
\text { Video making [33], } \\
\text { Sketch [2] }\end{array}$ & $\begin{array}{l}\text { Programming }[6,9,15,16,21,23], \\
\text { Robot-building }[6,22,23,49,52], \\
\text { 3D drawing/printing }[6,8,16,18,49], \\
\text { Circuit building }[9,15,16,21,52], \\
\text { Video making [18] }\end{array}$ \\
\hline Evaluation & $\begin{array}{l}\text { External feedback }[1-3,14,20,59] \text {, } \\
\text { Presentation }[7,12,36] \text {, } \\
\text { Competition }[19,36] \\
\text { Evaluation Framework }[4,10]\end{array}$ & $\begin{array}{l}\text { Presentation }[6,8,11,15,16,18] \text {, } \\
\text { Self-evaluation }[16,18]\end{array}$ \\
\hline Overarching & $\begin{array}{l}\text { Project Planning }[1,14,59] \text {, } \\
\text { Track progress }[4] \text {, } \\
\text { Set learning goals }[5] \\
\text { Self-reflect [4] }\end{array}$ & \\
\hline
\end{tabular}

more about finding an idea that was suitable for the construction activities.

All selected ME practices involve activities that revolve around creation through new technologies. Six practices involved programming activities [6, 9, 15, 16, 21, 23], five practices involved robot-building activities of which four utilised robotics kits $[6,22$, 23,49 ] and one [52] aimed to build a robot through wearable technologies. Five practices involved $3 D$ drawing and printing activities $[6,8,16,18,49]$, and five practices involved circuit building with microcomputers and basic electronic components [9, 15, 16, 21, 52] into their prototype creation activities. Moreover, Dolomiti Digital Camp [18] includes an activity in which participants make a video of their working prototype.

Lastly, practices include evaluation activities. In six practices students needed to present their work, either through a posterpresentation [8] or classroom presentations $[6,11,15,16,18]$. Moreover, two practices involve activities in which the students selfevaluate their work: in Designweek@school [16] students need to reflect on the sustainability of their invention and in Dolomiti Digital Camp [18] students use a Business Model Canvas to evaluate their start-up idea.

\subsection{Teacher Role}

Teaching roles concern all roles that teachers play during the educational learning process to promote student learning. This revolves around the question: How is the teacher or facilitator facilitating the students' learning?

$D T$ practices $(N=16)$. The core role for teachers in DT practices is giving feedback on the ideas of students. This can scaffold the students' process [58], facilitates the development of self-reflection [45] and self-assessment [43]. Five practices [1, 4, 5, 10, 14] also incorporated assessment activities, making assessment a task of the teacher. We will discuss the activities in more detail in section 3.4. In six of the selected practices [1-3, 10,14, 20], activities include collaborations with organisations, local communities, or individuals. To host these practices, teachers have to organise connections with these groups. Most practices don't use traditional methods of transferring knowledge, such as lectures. However, in three practices $[19,33,36]$ the teacher still uses these methods to explain a topic. Three practices $[4,10,59]$ give teachers guidelines for the implementation of DT in their classroom. This allows teachers to design DT projects that fit their teaching style and the needs of their students. Moreover, Designathon [7] incorporates basic electronics as a tool for children to build prototypes with. For the students to be able to work with these, the teachers model how these electronics work. In turn, the teacher needs to diagnose if the students have gained the right knowledge to work with these electronics. Moreover, in Stanford's taking design thinking to schools project [33], the teacher has to diagnose whether the students have 
Table 5: Overview of the identified teacher roles in the $16 \mathrm{DT}$ and $12 \mathrm{ME}$ practices.

\begin{tabular}{|l|l|l|}
\hline Teacher role & DT $\mathbf{( N = 1 6 )}$ & ME (N=12) \\
\hline Give feedback & {$[1-3,5,7,10,12-14,17,19,20,33,36,59]$} & {$[6,8,9,11,15,16,18,21,49,52]$} \\
\hline Assessment & {$[1,4,5,10,14]$} & {$[6,8]$} \\
\hline Organize & {$[1-3,10,14,20]$} & {$[6,15,18,49,52]$} \\
\hline Explain & {$[19,33,36]$} & {$[6,9,11,16,18,49]$} \\
\hline Design & {$[4,10,59]$} & \\
\hline Model & {$[7]$} & {$[18,22,23,49]$} \\
\hline Diagnosing & {$[7,33]$} & {$[6,8,9,15,16,18,22,23,49]$} \\
\hline Reflect & {$[4]$} & \\
\hline
\end{tabular}

gained the correct knowledge on geography that they can implement in their project. Lastly, Agency by Design [4] also incorporates materials that allow teachers to self-reflect on their teaching methods. This can be beneficial, as teaching DT processes might be new for teachers [25].

ME practices $(N=12)$. In the selected ME practices, students often need background knowledge to successfully complete the learning activities. Therefore, teachers need to explain the theory that underlies the activities in six practices [6, 9, 11, 16, 18, 49]. In four practices [18, 22, 23, 49], the teacher also models how an activity should be done by, for example, creating their own robot with a robot construction kit or making their own scratch program. The biggest difference in teacher roles between approaches lies in diagnosing whether students have obtained this practical knowledge enabling them to carry out a making activity. As all practices involve some sort of learning of technical skills, this is a core teacher role of the selected ME practices.

However, the teacher roles also have overlap: During the process, giving feedback is just as important in ME as in DT processes. Five of the ME practices [6, 15, 18, 49,52] work together with outside institutions or are hosted by companies external to the school, here teachers have to organise this collaboration. Lastly, two practices $[6,8]$ incorporate activities in which the teacher assesses.

\subsection{Assessment}

Assessment concerns the assessment of the extent to which a student has achieved the learning objectives. Evaluations of effectiveness of a practice were excluded. We made a distinction between; formative assessment that occurs during the learning process to diagnose learning progress; summative assessment at the end of the learning process to measure learning outcomes; and ipsative assessment that compares a learner's current with previous performance (see Table 6).

Table 6: Overview of the identified assessment methods in the $16 \mathrm{DT}$ and $12 \mathrm{ME}$ practices.

\begin{tabular}{|l|l|l|}
\hline Assessment type & DT (N=16) & ME (N=12) \\
\hline Formative & Observation $[4]$ & Observation $[6,8]$ \\
\hline Summative & & \\
\hline Ipsative & $\begin{array}{l}\text { Self-Reflection }[1,4,10,14] \\
\text { Competency Assessment [5] }\end{array}$ & \\
\hline
\end{tabular}

$D T$ practices $(N=5)$. Out of the 16 DT practices, we found five practices that described their assessment procedures. Designed by
Kids [5] utilises a formative assessment method by assessing different predefined competencies during different phases of the design process. The Impact Club Initiative [1], Design Thinking toolkit [10], and Progetto SET - Scuola e Territorio [14] use an ipsative method by letting their students self-reflect on their learning outcomes guided through reflection templates. Agency by Design [4] includes assessment methods for both student and teacher: it provides observation grids for the teacher to assess the process of the student, but it also provides self-reflection templates for both student and teacher.

$M E$ practices $(N=2)$. Of the twelve ME practices, two practice describes how they assess the students' learning outcomes. Maker@Scuola [8] and Kogaion Academy [6] provide the teacher with observation grids to formatively assess the students during their process. These observation grids include factors like collaboration, leadership, motivation, and inventiveness.

\subsection{The connected qualities of DT and ME}

From these results, we developed an overview (see Figure 1) to showcase the identified connections of the qualities of both DT and $\mathrm{ME}$ in early education. The diagram represents the following: the coded learning objectives set by the 28 selected practices; the learning activities that aim to fulfil these objectives within four phases and the corresponding role of the teacher within these; and how the learning of the students is assessed within the practice. Through the coloured lines in the diagram, we can see that the learning objectives are addressed by activities in different process phases and are assessed using various methods.

Some of the DT and ME processes that we analysed addressed learning objectives throughout multiple phases and activities. A student might gain critical thinking competency by doing interviews in the research phase, by thinking about the users in an ideation activity, or by self-evaluating their concept in an evaluation activity. Moreover, interpersonal skills, self-regulation, and professional skills get established through activities that are repeated throughout the process. However, as the analysed practices in this review are just a subset of all DT and ME practices, we can imagine more activities in which students can attain the learning objectives. For example, some students might develop critical thinking skills through research activities online or by conducting research with externals.

While 18 practices were connected to the school curriculum, only five provided information on their assessment procedures. Next 


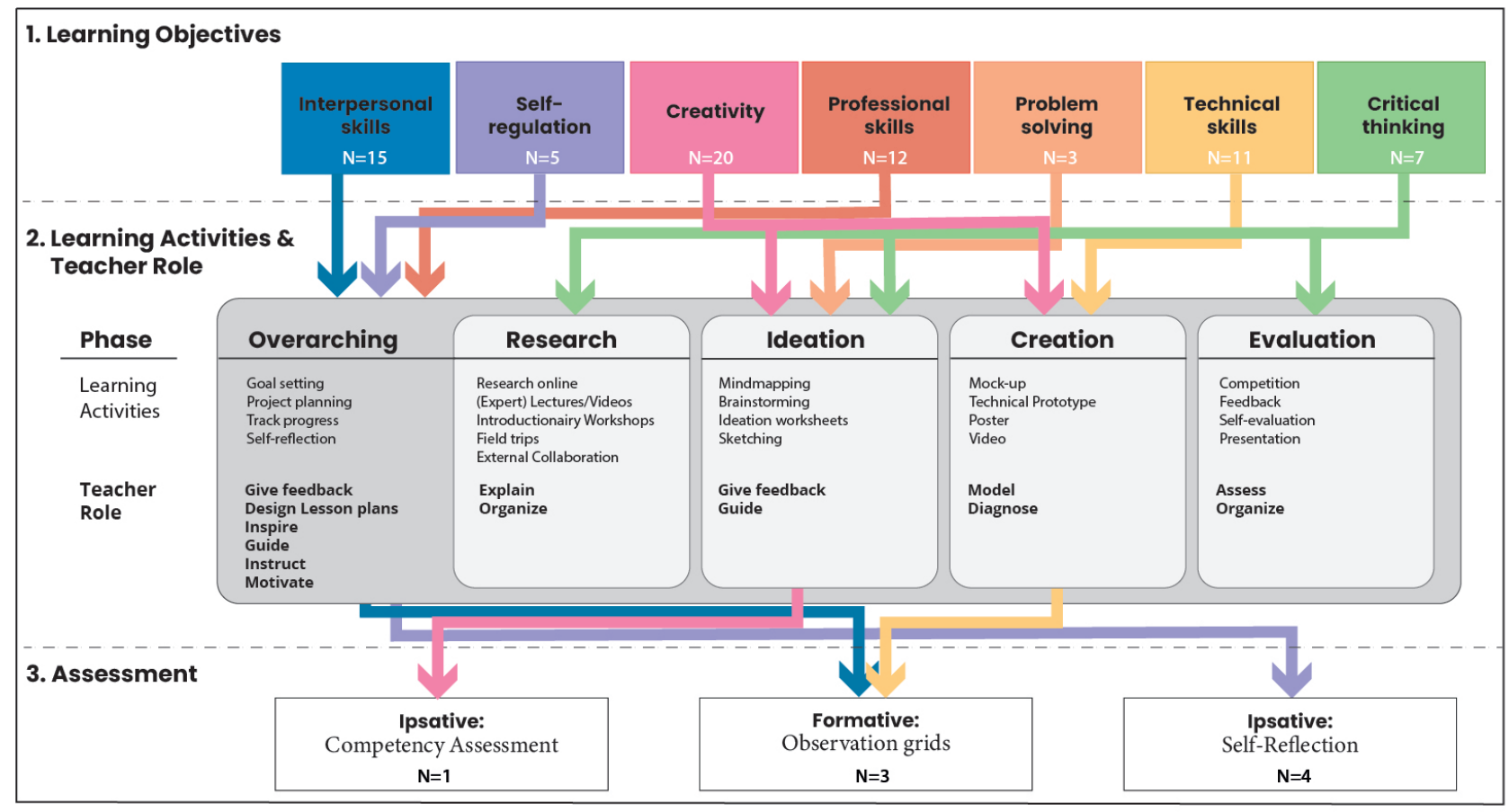

Figure 1: Overview of combined coded DT and ME qualities and the connections between Learning Objectives, Learning Activities, and Assessment Activities based upon constructive alignment [28], and the teacher roles during the different phases of the DT and ME learning process.

to which, two informal practices, a summer school [6] and afterschool program [1], detailed their assessment activities. Through the marked numbers of practices and coloured arrows in Figure 1, we see that many learning objectives are not assessed. However, assessment in DT and ME practices might not be a straight-forward task. Previous research has shown that it is not always clear for teachers which learning goals are targeted [25] within DT practices.

This overview serves as a descriptor of the constructive alignment [28] within a subset of DT and ME practices in early education. It can be used by curriculum designers and teachers to reflect on the ways how learning objectives, learning activities, the teachers' role, and assessment can connect within DT and ME teaching processes. And they can use it as a tool to guide design decision-making by reflecting on how these decisions fit within the overview or expand upon it.

\section{DISCUSSION}

\subsection{The DT and ME Curriculum Blueprint (Table 7)}

Through the overview of the analysed practices (Figure 1), we have seen that within the analysed practices not all components are connected; learning objectives are only occasionally assessed. To be able to create a consistent DT and ME curriculum that can be implemented in a formal educational setting each component of the curriculum needs to be balanced and aligned with each other. Therefore, a deliberate alignment between the planning of learning activities, the learning outcomes, and the way these learning outcomes are assessed needs to be made [28]. To support curriculum designers and teachers in this, we suggest the DT and ME Curriculum Blueprint, an initial structure (shown in Table 7) that aims to support the reflection on the inherent relationships between eleven components of a curriculum. The blueprint is based on the previously discussed concept of constructive alignment [28]; the curricular spiderweb [65], a framework for curriculum development; and the identified phases that overlap DT and ME. Subsequently, the qualities of DT and ME that are highlighted within this review can be placed in this tool. We have filled in three rows to showcase it's potential use. In the upcoming sections, we will clarify each column of the blueprint.

Design phase \& thinking mode. As the design of a DT and/or ME practice has to abide by the temporal sequence of the process phases of these approaches, the first column of the Curriculum Blueprint encompasses these phases. It allows designers to put the learning activities in a sequence. During the different phases of design and making processes, the students' thinking mode shifts between divergent and convergent [35]. When designing appropriate learning activities, it can also be beneficial to reflect on which thinking mode to support.

Learning objective \& taxonomy level. According to the principle of constructive alignment, curriculum development can take place in order [28]. First, you set the learning goal, which is a combination between a learning objective and taxonomy level, a hierarchy that sorts learning objectives into levels of complexity and specificity. Curriculum designers might pick one of the learning objectives that is listed in Figure 1, they might consider one of the 21st-century 
Table 7: DT and ME Curriculum Blueprint composed of curriculum components. Components are adapted from Biggs' Constructive Alignment [28] and the Curricular Spiderweb [65]. Three rows are filled in to illustrate its use.

\begin{tabular}{|c|c|c|c|c|c|c|c|c|c|c|}
\hline Phase & $\begin{array}{l}\text { Thinking } \\
\text { Mode }\end{array}$ & $\begin{array}{l}\text { Learning } \\
\text { Objective }\end{array}$ & Taxonomy & Assessment & $\begin{array}{l}\text { Learning } \\
\text { Activity }\end{array}$ & Grouping & $\begin{array}{l}\text { Teacher } \\
\text { Role }\end{array}$ & Location & Material & Time \\
\hline Research & Convergent & $\begin{array}{l}\text { Critical } \\
\text { Thinking }\end{array}$ & Remember & $\begin{array}{l}\text { Summative: } \\
\text { Class discussion }\end{array}$ & $\begin{array}{l}\text { Lecture on } \\
\text { project topic }\end{array}$ & Individual & Explain & Classroom & $\begin{array}{l}\text { Digital Board, } \\
\text { Folders }\end{array}$ & 1 hour \\
\hline Ideation & Convergent & Creativity & Apply & $\begin{array}{l}\text { Formative: } \\
\text { Observations }\end{array}$ & Brainstorming & 4 students & Feedback & Classroom & Post-its Paper & 2 hours \\
\hline Ideation & Divergent & Creativity & Analyze & $\begin{array}{l}\text { Summative: Ar- } \\
\text { gumentations in } \\
\text { report }\end{array}$ & $\begin{array}{l}\text { Draw connec- } \\
\text { tions between } \\
\text { ideas }\end{array}$ & 4 students & Feedback & Classroom & Post-its Paper & 1 hour \\
\hline
\end{tabular}

skills [64] or formulate an objective themselves. This objective together with a taxonomy level, allows the designer to rationalize what level of understanding is aimed for. Taxonomies like the Bloom [46] or SOLO [28] taxonomy can be applied here. When choosing a taxonomy level, curriculum developers need to take the prior knowledge level of students' into account to scaffold [27] their learning. We illustrate how learning and assessment activities might change based on different taxonomy levels in Table 7.

Assessment. Second, assessment activities need to be designed. In deciding the assessment tasks, it is necessary to judge the extent to which they embody the target learning level of the students, and how well they lend themselves to evaluating the students' performance. In Figure 1, we see that most practices employ ipsative self-assessment through reflection or formative assessment through observation grids. Other forms of assessment need to be considered. For example, to support ipsative assessment, a portfolio might be created to allow students to better reflect on their growth [29]. Moreover, peer-assessment might be a way to give students more ownership over their learning. However, the personal biases of the students need to be accounted for [67]. Surprisingly, we have not identified summative assessment activities within our review sample. This might be because established summative assessment activities, such as exams, are not suitable for DT and ME practices. However, we can imagine summative assessment activities which have can have utility when implemented in DT and ME practices in early education. For example, assessment through a rubrics or report writing. Lastly, for these assessment strategies to be successful, the connection between assessment and the projected learning outcomes need to be communicated to the students.

Learning Activity \& its elements. Third, the learning activities and educational materials need to be designed. The learning activities should be able to support the students in reaching the learning goal. Additionally, the teachers, peers, students, provided environment and materials, and time that is given all influence the outcome of the activities [65]. Within Table 7, we dedicated columns to all these aspects of the learning activity, so the curriculum designer can consider these elements when creating the supporting materials. For example, students can work individually or in groups. When students work in groups, materials can be provided to support collaborative processes such as decision making, task division, or project planning [48]. The teacher plays a pivotal role within DT and ME processes. However, teachers who have been trained in traditional teaching methods might have difficulties adapting to the different teaching styles embedded into these more open-ended processes [25]. Therefore, designers need to provide teachers with the appropriate materials to carry out each activity. Furthermore, the environment and provided materials have an impact on how the activities can play out. ME practices carry a wider variety and more costly materials than DT practices [55]. Lastly, time plays a meaningful role in the implementation of a learning activity. Students need time for ideation and experimentation. However, there needs to be a balanced time distribution over the various learning activities.

\subsection{Future work and limitations.}

This review aims to add to the body of work that tries to understand and theorise about designing and making approaches within the educational context. Specifically, it expands on the limited knowledge on DT and ME in early education. While most review papers analyse academic research, we decided to take a slightly different approach in which we included detailed descriptions of practices in our review. Through this, we are able to give insight into the way in which DT and ME approaches are pragmatically implemented. However, our review isn't exhaustive. The qualities presented in the overview in Figure 1 only demonstrate the codes we have identified within a representative set of practices. There is a possibility that the keywords (see Table 1) and publication venues that we have used have constrained our results. For example, we have found few practices related to FabLearn that met our inclusion criteria. Therefore, we believe that this overview can be developed further. Either through expansion of practices or codes. For example, only four process phases have been coded based upon the activities described within the practices. However, other DT process models, such as that of d.school [66] or the double diamond [53] incorporate more phases that could be designed for. For example, we have not found any specific descriptions of activities in which students synthesise the outcomes of their research activities. By adding the 'synthesize' phase, as described in the double diamond [53], we can become more aware of the need for activities that support this process. Additionally, designing is often seen as an iterative approach in which a designer can move back and forth between different phases [42]. The current version of the DT and ME Curriculum Blueprint doesn't provide concrete support for teachers to anticipate and implement iterations.

Finally, in our review we might have been subject to biases: when choosing practices we mainly focused on practices in countries that were included in the European project that this review is part of (Greece, Italy, the Netherlands, and Romania). Moreover, the involved researchers might have inclined to choose practices 
that were familiar to them. To account for cultural differences and differences in educational systems, this review can be expanded by including practices from a wider section of countries. Moreover, different second coders have been involved in this review. These reviewers were chosen based on their expertise. This could have lead to differences in knowledge on the practices of the coders. All second coders familiarised themselves with the practices. And through discussion with the first coder we attempted to avoid any inconstancy in understanding.

\section{CONCLUSION}

Previous research has examined and described various qualities of DT and ME. The contribution of the present paper lies in the focus on examining the implementation and alignment of some of the core elements of learning practices. We analysed 28 contemporary practices that incorporated DT or ME aimed at students 8 to 14 years old to lay bare their learning objectives, learning activities, the teacher's role, and their assessment activities. First, we present a diagram that combines DT and ME and illustrates the connections between and alignment of these aspects (see Figure 1) to inform (educational) design practitioners on commonly made design decisions. Secondly, we propose the DT and ME Curriculum Blueprint (see Table 7) that allows practitioners to reflect on the different interlinked components of a curriculum when designing an educational program that combines DT and ME.

\section{ACKNOWLEDGMENTS}

This work is part of the DESIGN FUTURES project and has been partially funded by the Erasmus+ programme of the European Union under the Project ID: 2019-1-NL01-KA201-060353.

\section{REFERENCES}

[1] 2009. Impact Clubs Initiative. https://www.noi-orizonturi.ro/tineri/cluburileimpact/

[2] 2009. My Machine. https://mymachine-global.org/

[3] 2009. Tools at schools: Integrating Design Thinking in Education. http://tools-atschools.com/about

[4] 2012. Agency by Design. http://www.agencybydesign.org/

[5] 2012. Designed by Kids: het uitwerken van een spelconcept. https //www.wetenschapsknooppuntzh.nl/blog/designed-by-kids-het-uitwerkenvan-een-spelconcept/

[6] 2013. Kogaion Academy. https://kogaionacademy.ro/programe/tal/

[7] 2014. Designathon Works. https://www.designathon.nl/

[8] 2014. Maker@Scuola. http://www.indire.it/en/progetto/maker-at-school/

[9] 2015. CO4LAB. http://co4lab.helsinki.fi/

[10] 2015. Design Thinking Toolkit. http://www.talenteducation.eu/toolkitforteachers/ designthinking/nl/

[11] 2015. Fondul Științescu. https://stiintescu.ro/

[12] 2015. Happiness Makers: what we teach. https://www.happinessmakers.com/whatwe-teach

[13] 2016. Activista I CAN. https://www.dfcspain.org/

[14] 2016. Progetto SET - Scuola e Territorio. https://www.ic8modena.edu.it/scuolaterritorio-set/

[15] 2016. Samsung Smart Future - Smart Coding/Smart Thinking. https: //news.samsung.com/global/smart-thinking-project-helps-italian-studentsdesign-their-future

[16] 2017. Designweek@school. https://designweekatschool.nl/

[17] 2017. KidsCan! Innovation camp. https://kidscanproject.weebly.com/onlinecamp-2020-lesson-guide.html

[18] 2018. Dolomiti Digital Camp. http://www.pacollaborative.com/portfolio-items/ dolomiti-digital-camp/

[19] 2018. Eureka! Past, Present and Future! https://sites.google.com/a/craigclowan. org.uk/eureka-past-present-and-future/home

[20] 2018. Nemesis. https://nemesis-edu.eu/

[21] 2018. Vodafone Generation Next. https://www.vodafonegenerationnext.gr/
[22] 2019. Eduact. https://eduact.org/en/workshops/

[23] 2019. The Playful Robotics Workshops (PlayRobs). https://comnplayscience.eu/ app/practice/13

[24] Nancy E Adams. 2015. Bloom's taxonomy of cognitive learning objectives. fournal of the Medical Library Association: FMLA 103, 3 (2015), 152.

[25] Tilde Bekker, Saskia Bakker, Iris Douma, Janneke Van Der Poel, and Koen Scheltenaar. 2015. Teaching children digital literacy through design-based learning with digital toolkits in schools. International fournal of Child-Computer Interaction 5 (2015), 29-38.

[26] Yoav Bergner, Samuel Abramovich, Marcelo Worsley, and Ofer Chen. 2019. What Are the Learning and Assessment Objectives in Educational Fab Labs and Makerspaces?. In Proceedings of FabLearn 2019 (New York, NY, USA) (FL2019). Association for Computing Machinery, New York, NY, USA, 42-49. https: //doi.org/10.1145/3311890.3311896

[27] Laura E Berk and Adam Winsler. 1995. Scaffolding Children's Learning: Vygotsky and Early Childhood Education. NAEYC Research into Practice Series. Volume 7. ERIC.

[28] John Biggs. 1996. Enhancing teaching through constructive alignment. Higher education 32, 3 (1996), 347-364.

[29] Osman Birgin and Baki Adnan. 2007. The use of portfolio to assess student's performance. Fournal of Turkish science education 4, 2 (2007), 75-90.

[30] Paulo Blikstein. 2013. Digital fabrication and 'making' in education: The democratization of invention. FabLabs: Of machines, makers and inventors 4, 1 (2013), $1-21$.

[31] Paulo Blikstein and Dennis Krannich. 2013. The Makers' Movement and FabLabs in Education: Experiences, Technologies, and Research. In Proceedings of the 12th International Conference on Interaction Design and Children (New York, New York, USA) (IDC '13). Association for Computing Machinery, New York, NY, USA, 613-616. https://doi.org/10.1145/2485760.2485884

[32] Virginia Braun and Victoria Clarke. 2006. Using thematic analysis in psychology. Qualitative research in psychology 3, 2 (2006), 77-101.

[33] Maureen Carroll, Shelley Goldman, Leticia Britos, Jaime Koh, Adam Royalty, and Michael Hornstein. 2010. Destination, imagination and the fires within: Design thinking in a middle school classroom. International fournal of Art \& Design Education 29, 1 (2010), 37-53.

[34] Eva Eriksson, Ole Sejer Iversen, Gökçe Elif Baykal, Maarten Van Mechelen, Rachel Smith, Marie-Louise Wagner, Bjarke Vognstrup Fog, Clemens Klokmose, Bronwyn Cumbo, Arthur Hjorth, Line Have Musaeus, Marianne Graves Petersen, and Niels Olof Bouvin. 2019. Widening the Scope of FabLearn Research: Integrating Computational Thinking, Design and Making. In Proceedings of the FabLearn Europe 2019 Conference (Oulu, Finland) (FabLearn Europe '19). Association for Computing Machinery, New York, NY, USA, Article 15, 9 pages. https://doi.org/10.1145/3335055.3335070

[35] Gabriela Goldschmidt. 2016. Linkographic Evidence for Concurrent Divergent and Convergent Thinking in Creative Design. Creativity Research fournal 28, 2 (2016), 115-122. https://doi.org/10.1080/10400419.2016.1162497 arXiv:https://doi.org/10.1080/10400419.2016.1162497

[36] Dimitris Grammenos. 2016. Future Designers: A Rollercoaster for the Mind. Interactions 23, 1 (Dec. 2016), 58-63.

[37] Colin M Gray. 2013. Factors That Shape Design Thinking. Design and Technology Education 18, 3 (2013), 8-20.

[38] Idit Ed Harel and Seymour Ed Papert. 1991. Constructionism. Ablex Publishing.

[39] Mikkel Hjorth, Rachel Charlotte Smith, Daria Loi, Ole Sejer Iversen, and Kasper Skov Christensen. 2016. Educating the Reflective Educator: Design Processes and Digital Fabrication for the Classroom. In Proceedings of the 6th Annual Conference on Creativity and Fabrication in Education (Stanford, CA, USA) (FabLearn '16). Association for Computing Machinery, New York, NY, USA, 26-33. https://doi.org/10.1145/3003397.3003401

[40] Ole Sejer Iversen, Rachel Charlotte Smith, Paulo Blikstein, Eva-Sophie Katterfeldt, and Janet $C$ Read. 2016. Digital fabrication in education: Expanding the research towards design and reflective practices. International fournal of Child-Computer Interaction 5, 1-2 (2016), 1-2.

[41] Megumi Iwata, Kati Pitkänen, Jani Ylioja, Iván Sánchez Milara, and Jari Laru. 2019. How Are Mobile Makerspaces Utilized in Schools?. In Proceedings of the FabLearn Europe 2019 Conference (Oulu, Finland) (FabLearn Europe '19). Association for Computing Machinery, New York, NY, USA, Article 14, 3 pages. https://doi.org/ $10.1145 / 3335055.3335069$

[42] David H Jonassen. 2008. Instructional design as design problem solving: An iterative process. Educational Technology (2008), 21-26.

[43] Charles Juwah, Debra Macfarlane-Dick, Bob Matthew, David Nicol, David Ross, and Brenda Smith. 2004. Enhancing student learning through effective formative feedback. The Higher Education Academy 140 (2004), 1-40.

[44] Eva-Sophie Katterfeldt, Nadine Dittert, and Heidi Schelhowe. 2015. Designing digital fabrication learning environments for Bildung: Implications from ten years of physical computing workshops. International fournal of Child-Computer Interaction 5 (2015), 3-10. https://doi.org/10.1016/j.ijcci.2015.08.001 Digital Fabrication in Education. 
[45] Janet L Kolodner. 2002. Learning by design ${ }^{\mathrm{TM}}$ : Iterations of design challenges for better learning of science skills. Cognitive Studies 9, 3 (2002), 338-350.

[46] David R Krathwohl and Lorin W Anderson. 2009. A taxonomy for learning, teaching, and assessing: A revision of Bloom's taxonomy of educational objectives. Longman.

[47] Toshiaki Kurokawa. 2013. Design thinking education at universities and graduate schools. Science \& Technology Trends Quarterly Review 46 (2013), 50-63.

[48] Ann Ledwith, Raymond Lynch, et al. 2017. How design education can support collaboration in teams. In DS 88: Proceedings of the 19th International Conference on Engineering and Product Design Education (E\&PDE17), Building Community: Design Education for a Sustainable Future, Oslo, Norway, 7 \& 8 September 2017. 014-019.

[49] Jackie Marsh, Hans Christian Arnseth, and Kristiina Kumpulainen. 2018. Maker literacies and maker citizenship in the MakEY (Makerspaces in the early years) project. Multimodal Technologies and Interaction 2, 3 (2018), 50.

[50] L. Martin. 2015. The Promise of the Maker Movement for Education. Fournal of Pre-College Engineering Education Research 5 (2015), 30-39.

[51] Sylvia Libow Martinez and Gary Stager. 2013. Invent to learn. Making, Tinkering, and Engineering in the Classroom. Torrance, Canada: Construting Modern Knowledge (2013).

[52] Mandy McLean, Tyler Susko, Danielle Harlow, and Julie Bianchini. 2017. Dancing Robots: A Collaboration Between Elementary School and University Engineering Students. In Proceedings of the 7th Annual Conference on Creativity and Fabrication in Education (Stanford, CA, USA) (FabLearn '17). Association for Computing Machinery, New York, NY, USA, Article 17, 4 pages.

[53] Dan Nessler. 2018. How to apply a design thinking, HCD, UX or any creative process from scratch. https://medium.com/digital-experience-design/howto-apply-a-design-thinking-hcd-ux-or-any-creative-process-from-scratchb8786efbf812

[54] Kevin M Oliver. 2016. Professional development considerations for makerspace leaders, part one: Addressing "what?" and "why?". TechTrends 60, 2 (2016), $160-166$.

[55] Sofia Papavlasopoulou, Michail N Giannakos, and Letizia Jaccheri. 2017. Empirical studies on the Maker Movement, a promising approach to learning: A literature review. Entertainment Computing 18 (2017), 57-78.
[56] Guy Paré, Marie-Claude Trudel, Mirou Jaana, and Spyros Kitsiou. 2015. Synthesizing information systems knowledge: A typology of literature reviews. Information \& Management 52, 2 (2015), 183-199.

[57] Jean Piaget. 1964. Cognitive development in children: Piaget. Development and learning. Journal of Research in Science Teaching 2 (1964), 176-186.

[58] Sonia M. Gómez Puente, Michiel Van Eijck, and Wim Jochems. 2013. Empirical validation of characteristics of design-based learning in higher education. International fournal of Engineering Education 29, 2 (2013), 491-503.

[59] Hayagreeva Rao, Phanish Puranam, and Jasjit Singh. 2020. Does Design Thinking Training Really Increase Creativity? Results from an Experiment with MiddleSchool Students. INSEAD Working Paper No.2020/11/STR (2020). https://doi.org/ $10.2139 /$ ssrn.3543943v

[60] Rim Razzouk and Valerie Shute. 2012. What Is Design Thinking and Why Is It Important? Review of Educational Research 82, 3 (2012), 330-348. http://www. jstor.org/stable/23260048

[61] Rachel Charlotte Smith, Ole Sejer Iversen, and Mikkel Hjorth. 2015. Design Thinking for Digital Fabrication in Education. Int. f. Child-Comp. Interact. 5, C (Sept. 2015), 20-28.

[62] Rachel Charlotte Smith, Ole Sejer Iversen, and Rune Veerasawmy. 2016. Impediments to Digital Fabrication in Education: A Study of Teachers' Role in Digital Fabrication. Int. F. Digit. Lit. Digit. Competence 7, 1 (Jan. 2016), 33-49. https://doi.org/10.4018/IJDLDC.2016010103

[63] Mana Taheri, Thomas Unterholzer, Katharina Hölzle, and Christoph Meinel. 2016. An educational perspective on design thinking learning outcomes. In ISPIM Innovation Symposium. The International Society for Professional Innovation Management (ISPIM), 1

[64] Annette Thijs, Petra Fisser, and Monique van der Hoeven. 2014. 21e eeuwse vaardigheden in het curriculum van het funderend onderwijs. (2014).

[65] Jan van den Akker. 2004. Curriculum perspectives: An introduction. In Curriculum landscapes and trends. Springer, 1-10.

[66] Natalie Whearley. 2020. (archival resource) Design Thinking Bootcamp Bootleg. https://dschool.stanford.edu/resources/the-bootcamp-bootleg

[67] Irfan Yurdabakan. 2011. The investigation of peer assessment in primary school cooperative learning groups with respect to gender. Education 3-13 39, 2 (2011), $153-169$. 